\title{
COVID-19 and the Challenges in World's Largest Vaccination Drive in India
}

\author{
Archana Yadav \\ Institute of Business Management, GLA University, Mathura - 281 406, Uttar Pradesh, India.
}

\begin{abstract}
COVID-19's second wave has placed India into a state of emergency. Since the beginning of April 2021, the country has seen an extraordinary influx of corona positive cases. Due to COVID-19, our country is in the midst of the world's worst crisis. Many reports and articles about the lack of hospital beds, oxygen cylinders, ICU beds, ventilators, and other medical supplies were published (both print and electronic) in this second wave, exposing the flaws in our country's healthcare system. On January 16, 2021, the Indian government launched the world's largest vaccination effort, but we still have a long way to go in vaccinating our 1.4 billion people. India, after China, is the world's second most populous country, accounting for approximately $\mathbf{1 7 . 5}$ percent of the global population. This post aims to emphasize the issues that our country is currently facing, as well as possible solutions to combat this deadly illness.
\end{abstract}

Keywords: COVID-19, Pandemic, Vaccination, India, Challenges, Vaccine shortage

*Correspondence: archana.yadav056@gmail.com

(Received: May 17, 2021; accepted: November 02, 2021)

Citation: Yadav A. COVID-19 and the Challenges in World's Largest Vaccination Drive in India. J Pure Appl Microbiol. 2021; 15(4):2431-2438. doi: 10.22207/JPAM.15.4.69

(C) The Author(s) 2021. Open Access. This article is distributed under the terms of the Creative Commons Attribution 4.0 International License which permits unrestricted use, sharing, distribution, and reproduction in any medium, provided you give appropriate credit to the original author(s) and the source, provide a link to the Creative Commons license, and indicate if changes were made. 


\section{INTRODUCTION}

"The US is planning Post-pandemic life. In India, we are trying not to die" - The Washington Post $^{1}$

The COVID-19 epidemic had become the world's most horrific pandemic. ${ }^{2}$ Many people's lives have been affected by this pandemic over the world ${ }^{3}$ and many people have died as a result of it. ${ }^{4}$ India's healthcare infrastructure has entirely failed. ${ }^{5}$ The main issue is that our country is seeing the worst outbreak of COVID in its history, with 19 cases reported across the country, and the death toll is also on the rise. ${ }^{6}$ The fatal virus had now spread to rural India, where there had been few cases during the first wave. According to official government data, about 45000 persons died in April 2021 as a result of the deadly second wave of coronavirus. ${ }^{7}$ There is widespread speculation that the true death toll is substantially higher than what the government reports.

Many theories are currently circulating as to why the number of COVID cases has suddenly increased during the second wave. According to some stories, the government was negligent in not taking the second wave seriously and pooling all of its resources to combat the epidemic. Some are blaming the outbreak on how casually and irresponsibly people have approached it since the beginning of the year, disregarding all COVID restrictions (by poking fun of social distancing norms, wearing masks properly, etc.). But the main line is that our entire country of 1.4 billion people $^{8}$ is struggling as a result of the deaths of millions of people caused by this dreadful illness in the previous year. Given the increased number of COVID cases, India's government is implementing a number of tough measures to prevent the virus from spreading among the country's enormous population.

Several government initiatives and steps have been implemented in the last year to combat the spread of this dangerous virus. However, considering the severity of the situation, all of our efforts appear to be inadequate. On January 16,2021 , our country launched the world's largest vaccination campaign. ${ }^{9,10}$ The first round of vaccinations was given to healthcare and frontline personnel. However, our country is currently experiencing a vaccine scarcity, and as a result, the government is unable to successfully begin vaccinating all people aged 18 and above in various parts of India.

This research article aims to present the current miserable situation in India as a result of the second wave of COVID-19. The current research also discusses the many vaccines that are given to people in various parts of India. The COVID-19 outbreak has exposed severe flaws in healthcare systems in various nations around the world. ${ }^{11}$ Manufacturing affordable and safe vaccinations for all nations ${ }^{12,13}$ is critical, as is assuring their supply to low-income countries. ${ }^{14,15,16}$ This epidemic has undoubtedly resulted in a global health emergency, $18,3,12$ as well as economic upheaval.

When COVID first appeared on the scene last year, the World Health Organization instantly proclaimed it a pandemic. 19,20,21 "Viruses have the potential to cause irreparable loss to human beings". ${ }^{22}$ The coronavirus, which originated in Wuhan city in the People's Republic of China, ${ }^{23,10}$ has affected billions of people around the world to date. On January 30, 2020, the first COVID case in India was recorded in Trissur, Kerela. ${ }^{24}$ Since then, millions of people in India have been infected with this fatal virus.

\section{Current status of COVID-19 Second Wave in India}

"As COVID-19 devastates India, Deaths go undercounted." - The New York Times ${ }^{8}$

In just one day, on May 6, 2021, India experienced an all-time high of 4.12 lakh new COVID cases and approximately 4,000 deaths. ${ }^{25}$ COVID-19's second wave in India is now clearly turning into a devastating crisis that has nearly ruined and brought forward all of India's healthcare sector's flaws and weaknesses. ${ }^{8}$ The true death rate is now generally acknowledged in the media to be significantly higher than the publicly stated death rates. In India, the number of people who have died as a result of COVID-19 has risen to an all-time high. The irony is that in most parts of India, the number of deaths caused by this deadly virus is either overstated or disregarded. ${ }^{8}$

India is probably witnessing the most harrowing pandemic in many centuries, with many people dying without even receiving medical help due to a lack of hospital beds, a lack of life-saving oxygen, and the non-availability or scarcity of required medicines to fight COVID such as Remdesivir, among other things. ${ }^{8}$ The photos and ground reports from cremation grounds, 
crematoriums, and other locations in India provide a significantly harsher depiction of death figures, with dead people being cremated on a daily basis. There is even no place left in these cremation grounds, crematoriums, and different ghats where before cremation was carried out, according to reports from various parts of India. It is now being claimed that the parking lots or adjacent grounds of these crematorium grounds are being used to cremate and administer the final rites of COVID patients in some regions. It has also been reported from various hospitals across India that a large number of patients admitted to ICU died owing to a lack of oxygen supply or shortage. ${ }^{8,26,5}$ All of these data about India's current situation sound dreadful.

The number of cases in India was under control earlier this year due to the initially imposed complete statewide lockdown. ${ }^{8}$ However, the situation in India has deteriorated to a new perilous level this year as a result of COVID's second wave. This pandemic has sent shockwaves throughout our country, with no distinction between rich and poor in terms of individuals dying as a result of this dreadful illness. We may read stories, encounters, tragedies, and terrible experiences of people who had either recovered and survived from this fatal illness or had observed some of their loved ones losing the struggle against the virus in various newspapers, online news portals, forums, blogs, social media, and so on.

\section{COVID-19 Vaccines available for use in India}

India is the world's vaccine manufacturing superpower, producing over $60 \%$ of the world's total vaccinations, with the Serum Institute of India being the world's largest vaccine maker. ${ }^{26}$ Because of widespread anxiety that we will all be infected by a coronavirus sooner or later, ${ }^{27,28}$ the COVID-19 vaccine is being developed at extremely fast speed around the world. ${ }^{27,28}$ To combat this lethal virus, the creation of the COVID-19 vaccine necessitated assembling a massive amount of resources. ${ }^{29}$ In the United States, two vaccines (Pfizer - BioNTech and Moderna) were approved for emergency use in December of last year. ${ }^{30}$

Scientists have developed and produced vaccines at a historically unprecedented rate $^{31}$ due to a number of major factors, including the need to combat the COVID virus, the incredible amount of resources and efforts put forth by the global community at large to address this pandemic, and the use of innovative methods (both in terms of technologies and the most recent advancements in processes). ${ }^{27}$

Currently, two vaccinations are frequently utilised in India. ${ }^{32}$ The first is the Oxford AstraZeneca jab (also known as Covidshield in India), which is manufactured by Serum Institute of India, and the second is Covaxin, which is manufactured by Bharat Biotech in India. ${ }^{10,26,33}$ Covidshield, created by Serum Institute of India in collaboration with Oxford University, is the Indian version of Oxford's AstraZeneca. ${ }^{33}$ The Indian government just approved the use of the Russian-made Sputnik V vaccination in India. ${ }^{26,34}$ The vaccine has been accessible for emergency use in India since May $14^{\text {th }}$ this year, and the first dose was given in Hyderabad. ${ }^{34}$

Controversies around Vaccination drive in India With the outbreak of COVID-19 cases across the country - many questions about how to combat this pandemic situation have surfaced. Tragically, India has become the world's only country to report more than 4 lakh new coronavirus cases in a single day. ${ }^{26}$ Many people are now accusing the government of failing to recognise the gravity of the problem at the outset by failing to take necessary precautions despite several warnings from concerned authorities on the ferocity of the second wave of corona in India. ${ }^{33}$ Not only that, but people from all walks of life are questioning the government's choice to donate our country's manufactured vaccinations to other countries at a time when our vaccination campaign is failing and vaccine production is insufficient to meet the needs of our vast population..$^{8,33}$ On the one hand, the central government claims that there is no scarcity of vaccines for vaccination campaigns for all 18 and above persons, but numerous states admit and worry about vaccine shortages. ${ }^{33}$

According to reports, India has shipped 64 million doses of vaccinations to 85 countries as part of several government agreements inked between vaccine manufacturers and various countries, as well as the WHO-led Covax initiative. ${ }^{33,36}$ In the midst of much anguish and turmoil in our country due to a vaccine scarcity, the government's decision is being widely criticised across the country. Although, following the sudden increase 
in the number of positive cases in early April 2021, the government has temporarily stopped vaccine exports. $^{33}$

\section{Challenges Surrounding COVID-19 and Vaccination in India}

On January 16, 2021, India launched the world's largest COVID-19 vaccination campaign for frontline and healthcare workers. ${ }^{8,26,32}$ However, the country's vaccination programme is still struggling to keep up with the demand of catering to the requirements of our country's 1.4 billion people. ${ }^{8,37}$

The current second wave of COVID-19 is not only impacting India's huge population, but it has also sent shockwaves throughout the world's scientific community, which is equally shocked at this time. Although our country is currently facing numerous obstacles during this second wave of COVID-19, the following are some of the most pressing issues that require immediate government and public attention

Ensuring the supply of Vaccines as per demand

The Government of India recently announced the opening of vaccination for those aged 18 and above..$^{25,37}$ In addition to the prior three groups of healthcare and frontline workers, the government has now opened registration for vaccination of persons over the age of 18 starting on May 1, 2021. However, due to a supply deficit, many states, including Madhya Pradesh, the worst-affected Maharastra, and others, have already expressed reservations about starting vaccination ${ }^{37}$ of those aged 18 and above on May $1 .^{33,37}$

According to COWIN statistics, just about $10 \%$ of our overall population has been vaccinated so far. ${ }^{25}$ Our government faces a major hurdle in ensuring vaccine availability to a larger community and population of 1.4 billion people. The government faces yet another major challenge in securing a sufficient supply of vaccines to all states in order to meet people's wants and needs.

Catering to the requirements of our large population, which is nearly three times that of the United States ${ }^{25}$ is a major issue for us. Few experts believe the vaccine scarcity is the result of supply bottlenecks, as vaccine manufacturers may have taken additional orders from throughout the world while overestimating their production capability ${ }^{33}$. Since a result of the rapid surge in cases, our country now faces a vaccine shortage and supply crisis, as vaccine makers are unable to meet the increased demand.

The irony of the situation is that, despite India being one of the world's largest vaccine manufacturers, ${ }^{26,37}$ just about $10 \%$ of our population has received their first dose of vaccination. ${ }^{8,37}$ Our country's major challenge right now is to either make or import enough vaccinations to vaccinate at least the majority of our high-risk population.

\section{Preventing Black Marketing and Hoarding of all medical supplies}

Despite the fact that India has received over 3000 tonnes of foreign aid, there is still a scarcity of oxygen, beds in hospitals, vaccine shortages, and other issues. ${ }^{25}$ Our government must also control and stop people who see the current dreadful situation as an opportunity to make profit by selling high-demand items (such as oxygen cylinders and concentrators, BiPAP machines, remdesivir injection, and so on) at considerably higher costs. People are hoarding vital items like oxygen cylinders, Remdesivir injection, and other medications and selling them at much higher costs than usual, according to information from numerous sources. 96 oxygen concentrators were recently seized from a restaurant in Delhi's Khan market on May 7, 2021. ${ }^{32}$

Another important problem for the administration is to put a halt to the illegal and inhumane conduct that is being performed by some sick people all over India. Only a few examples have been documented in which doctors or medical students were found to be involved in selling medical supplies at inflated costs to the family and friends of critically ill and severely injured COVID patients. ${ }^{38}$ These individuals are a disgrace in the face of the great number of healthcare workers and other volunteers who are doing whatever they can to help as many people as possible.

\section{Keeping healthcare and frontline workers' motivation high}

We must recognise and honour the efforts of every corona warrior, whether they are healthcare professionals, police and administration personnel, bank employees, railway employees, and others who risk their lives every day to make the lives of people like us easier and more 
convenient. Special monetary rewards and other perks are now being offered to healthcare and frontline employees in several states as a modest token of appreciation for their actual hard work and efforts.

\section{Fear and Anxiety in Public Places}

People all across the world are experiencing a variety of health-related issues as a result of this fatal virus, ${ }^{39}$ such as anxiety, stress, sadness, insomnia, lack of sleep, paranoia, and so on. ${ }^{40}$ Given the current dire state of the pandemic in our country, we can safely predict that the situation will not improve in the near future. As a result, the government should adopt a variety of steps and run campaigns to improve people's mental health.

\section{Threat to Economic stability}

This worldwide pandemic is sending shockwaves and ringing bells over the world, offering serious threats and difficulties to not just public health but also economic stability ${ }^{4}$ and economic well-being in all of the world's countries. ${ }^{22}$ This pandemic will have a long-term negative impact on our economy. ${ }^{41}$ Our healthcare infrastructure, vaccine availability, government support, layoffs and wage reductions during the COVID-19 epidemic, and so on are all issues we face as a result of our vast population.

The Road Ahead: How Should India Prepare for New Waves?

Our country must prepare for a longterm battle against this deadly virus. ${ }^{41}$ People's mindsets are steadily shifting as they adhere to basic procedures such as social distance conventions and guidelines, avoiding unnecessary travel, keeping personal hygiene, and so on ${ }^{40}$ The Indian government has already restricted vaccine exports and is instead attempting to get medical supplies from overseas, such as testing kits, oxygen concentrators, and vaccines. ${ }^{5}$

UNICEF further stated that the unfortunate COVID-19 crisis should serve as a wake-up call to the entire world community, and that the international community should join hands to help India as much as possible. ${ }^{42}$ UNICEF is also helping our country by providing medical supplies such as face shields, face masks, and other items to assist the country in this unfortunate situation. ${ }^{42}$ DP World Group Chairman and CEO
Sultan Ahmad Bin Sulayem said that the company partnered with UNICEF because dealing with COVID-19 pandemic is “...humanity's biggest logistics challenge in living memory". ${ }^{42}$

To prevent the spread of this fatal virus, it is not only critical to create an effective vaccine, ${ }^{22}$ but it is also critical to ensure that these vaccines reach the largest possible population. Vaccination drives are currently in progress in a number of developed and developing countries around the world ${ }^{43}$ but there are still little efforts being made globally to develop strategies for the equitable distribution of COVID-19 vaccines in less developed countries. ${ }^{43}$ Experts recommend that India should accelerate its vaccination effort in states with a high number of illnesses or in the five states where recent elections were held. ${ }^{26}$

To ensure that all people are vaccinated, the current vaccination campaign must increase up the pace. ${ }^{33}$ If the country wants to reach its goal of vaccinating 80 percent of the population aged 18 and up, it will need to increase its vaccination rate by approximately 100 million doses every month. ${ }^{44}$

According to a research published in one of the biggest daily newspapers, ${ }^{44}$ at the current rate of vaccination, India will only be able to cover 30 percent of its people by the end of 2021. Adar Poonawalla, the CEO of Serum Institute of India stated that his institution provides almost $65-70$ million doses of vaccines to India every month, but that manufacturing needs to be increased to 100 million doses per month to meet the demands of our people. ${ }^{33}$ Within the next few weeks, India will need to ensure that all old people and people at high risk receive vaccination doses, and they may enlist the support of local authorities, NGOs, religious leaders, celebrities, and others to do so. ${ }^{33}$ This will prepare our large population in fighting against new waves of COVID-19 most strongly.

Since the start of the third phase of vaccination for everyone aged 18 and up in India, the country has been dealing with a serious shortage of vaccine doses, ${ }^{37}$ with reports of long lines and stampede-like situations coming from various vaccination locations across the country. Despite these obstacles, tens of thousands of people between the ages of 18 and 45 have received their first dose of vaccines. ${ }^{45}$ This research indicates that there is still hope for improvement, 
and our country may be able to overcome the current catastrophe in the next months if we can vaccinate the majority of our population.

"If India aims to vaccinate all adults by the end of 2021, the average daily doses should increase to atleast $6.8 \mathrm{mn}$ per day, 2.5 times the current rate" - The Hindu ${ }^{46}$

According to the report, by 2021, we will need to raise the production of the dosage used to vaccinate the majority of our population, particularly all adults (940 million people*2 doses). ${ }^{46}$

Obtaining herd immunity ${ }^{47}$ could be another key milestone in the fight against fresh Coronavirus waves. ${ }^{48}$ "It shows that only a proportion of a population needs to be immune (through overcoming natural infection or through vaccination) to an infectious agent for it to stop generating large outbreaks.". ${ }^{48}$ Policymakers and administrators in India should search for strategies to deal with the pandemic while simultaneously concentrating on establishing herd immunity. Information management and the use of advanced and cutting-edge technical innovation are also critical to preventing or at least reducing the incidence of such devastating pandemics in the future. ${ }^{49}$ In the future, it will ensure a quick response and prompt handling of such pandemics. ${ }^{49}$

The Indian government is pursuing a number of initiatives to increase vaccine manufacturing capacity, with a particular focus on building a fully digitalized and efficient system for vaccination registration and administration tracking. ${ }^{10}$ Currently, it appears that the only answer is to impose a severe statewide lockdown in order to stop the spread and cycle of this fatal illness and to help persons suffering with Corona recuperate faster by providing proper medical care and treatment. This is also mentioned in several papers and articles produced by international and national organisations. ${ }^{50}$ As our country is once again experiencing near-lockdown-like restrictions in many places, the country must pool all of its resources, heart, soul, and courage to combat this deadly virus.

\section{ACKNOWLEDGMENTS}

None.

\section{FUNDING}

None.

\section{DATA AVAILABILITY}

All datasets generated or analyzed during this study are included in the manuscript.

\section{ETHICS STATEMENT}

Not applicable.

\section{REFERENCES}

1. Saluja R. The U.S. is planning post-pandemic life. In India, we're trying not to die. 2021. https://www. washingtonpost.com/outlook/2021/04/27/indiacovidcrisis-america/

2. Paital B, Das K, Parida SK. Inter nation social lockdown versus medical care against COVID-19, a mild environmental insight with special reference to India. Sci Total Environ. 2020;728:138914. doi: 10.1016/j. scitotenv.2020.138914

3. Chakraborty C, Sharma AR, Bhattacharya M, Lee SS, Agoramoorthy G. COVID-19 vaccine: Challenges in developing countries and India's initiatives. Le Infezioni in Medicina. 2021;29(1):165-166.

4. Kashte S, Gulbake A, El-Amin III SF, Gupta A. COVID-19 vaccines: rapid development, implications, challenges and future prospects. Human cell. 2021;34(3):711-733. doi: 10.1007/s13577-021-00512-4

5. Ghosh B. COVID-19 second wave: Can India find a way out of its health nightmare? 2021. https://www. business-standard.com/article/current-affairs/indiassecond-coronavirus-wave-what-went-wrong-andisthere-a-way-out-121050300881_1.html

6. Lazarus JV, Ratzan SC, Palayew A, et al. A global survey of potential acceptance of a COVID-19 vaccine. Nat Med. 2021;27(2):225-228. doi: 10.1038/s41591-0201124-9

7. Bhasin S. 3.68 Lakh New COVID Cases In India, 3,417 Deaths; 1.99 Crore Total Cases: 10 Points. 2021. https://www.ndtv.com/india-news/coronavirus-368-lakh-covid-19-cases-in-india-3-417-deaths-in-24hours-1-99-crore-total-cases-so-far-2426829

8. Gettleman J, Yasir S, Kumar H, Raj S. As COVID-19 Devastates India, Deaths Go Undercounted. 2021. https://www.nytimes.com/2021/04/24/world/asia/ india-coronavirus-deaths.html

9. Bagcchi S. The world's largest COVID-19 vaccination campaign. Lancet Infect Dis. 2021;21(3):323. doi: 10.1016/S1473-3099(21)00081-5

10. Kumar VM, Pandi-Perumal SR, Trakht I, Thyagarajan SP. Strategy for COVID-19 vaccination in India: the country with the second highest population and number of cases. NPJ Vaccines. 2021;6(1):60. doi: 10.1038/ s41541-021-00327-2

11. Lancet T. Global governance for COVID-19 vaccines. Lancet. 2020;395(10241):1883. doi: 10.1016/S01406736(20)31405-7

12. Kaur SP, Gupta V. COVID-19 Vaccine: A comprehensive 
status report. Virus Res. 2020;288:198114. doi: 10.1016/j.virusres.2020.198114

13. Forni G, Mantovani A. COVID-19 vaccines: where we stand and challenges ahead. Cell Death \& Differ. 2021;28(2):626-639. doi: 10.1038/s41418-020-007209

14. Sharun K, Dhama K. COVID-19 vaccine diplomacy and equitable access to vaccines amid ongoing pandemic. Arch Med Res. 2021;52(7):761-763. doi: 10.1016/j. arcmed.2021.04.006

15. Hotez PJ, Bottazzi ME. Developing a low-cost and accessible COVID-19 vaccine for global health. PLoS Negl Trop Dis. 2020;14(7):e0008548. doi: 10.1371/ journal.pntd. 0008548

16. Nhamo G, Chikodzi D, Kunene HP, Mashula N. COVID-19 vaccines and treatments nationalism: Challenges for low-income countries and the attainment of the SDGs. Global Public Health. 2021;16(3):319-339. doi: 10.1080/17441692.2020.1860249

17. Jabaris SSL, Ananthalakshmi V. The current situation of COVID-19 in India. Brain, Behavior, \& Immunity-Health. 2021;11:100200. doi: 10.1016/j.bbih.2021.100200

18. Yan Y, Pang Y, Lyu Z, et al. The COVID-19 Vaccines: Recent Development, Challenges and Prospects. Vaccines. 2021;9(4):349. doi: 10.3390/vaccines 9040349

19. Singh R, Adhikari R. Age-structured impact of social distancing on the COVID-19 epidemic in India. arXiv preprint arXiv. 2020.

20. Dutta AK. Vaccine Against COVID-19 Disease-Present Status of Development. The Indian Journal of Pediatrics. 2020;87:810-816. doi: 10.1007/s12098020-03475-w

21. Pagliusi S, Jarrett $S$, Hayman B, et al. Emerging manufacturers engagements in the COVID-19 vaccine research, development and supply. Vaccine. 2020;38(34):5418-5423. doi: 10.1016/j. vaccine.2020.06.022

22. Belete TM. Review on up-to-date status of candidate vaccines for COVID-19 disease. Infect Drug Resist. 2021;14:151-161. doi: 10.2147/IDR.S288877

23. Foy BH, Wahl B, Mehta K, Shet A, Menon GI, Britto C. Comparing COVID-19 vaccine allocation strategies in India: A mathematical modelling study. International Journal of Infectious Diseases. 2021;103:431-438. doi: 10.1016/j.ijid.2020.12.075

24. Varghese GM, John R. COVID-19 in India: Moving from containment to mitigation. Indian J Med Res. 2020;151(2-3):136-139. doi: 10.4103/ijmr. IJMR_860_20

25. Today I. Coronavirus in India May 6, 2021: Lockdown in Rajasthan from May 10 till May 24. 2021. https://www. indiatoday.in/coronavirusoutbreak/story/coronavirusin-india-live-updatescoronavirus-news-covid19-casescovid-vaccinenews-1799339-2021-05-06

26. BBC. India coronavirus: Over-18s vaccination drive hit by shortages. 2021. https://www.bbc.com/news/ world-asia-india-56345591

27. Bloom DE, Cadarette D, Ferranna M, Hyer RN, Tortorice DL. How New Models Of Vaccine Development For COVID-19 Have Helped Address An Epic Public Health Crisis. Health Affairs. 2021;40(3):410-418. doi: 10.1377/hlthaff.2020.02012
28. Mukherjee R. Global efforts on vaccines for COVID-19: Since, sooner or later, we all will catch the coronavirus J Biosci. 2020;45(1):68. doi: 10.1007/s12038-02000040-7

29. Gupta I, Baru R. Economics \& ethics of the COVID-19 vaccine: How prepared are we? Indian Journal of Medical Research. 2020;152(1):153-155. doi: 10.4103/ ijmr.IJMR_3581_20

30. Painter EM, Ussery EN, Patel A, et al. Demographic characteristics of persons vaccinated during the first month of the COVID-19 vaccination program-United States, December 14, 2020-January 14, 2021. Morb Mortal Wkly Rep. 2021;70(5):174-177. doi: 10.15585/ mmwr.mm7005e1

31. Hotez PJ, Corry DB, Strych U, Bottazzi ME. COVID-19 vaccines: neutralizing antibodies and the alum advantage. Nat Rev Immunol. 2020;20(7):399-400. doi: 10.1038/s41577-020-0358-6

32. Sinha D. COVID-19 vaccination and challenges in India: Ahead of world's largest vaccine drive, medical experts explain what to expect. 2021. https:// www. financialexpress.com/lifestyle/health/covid19-vaccination-and-challenges-in-india-ahead-ofworldslargest-vaccine-drive-medical-experts-explainwhatto-expect/2170852/

33. Biswas M, Rahaman S, Biswas TK, Haque Z, Ibrahim B. Association of sex, age, and comorbidities with mortality in COVID-19 patients: a systematic review and meta-analysis. Intervirology. 2021 ;64(1): 36-47. doi: 10.1159/000512592

34. Desk IT. Will Sputnik Light, Russia's single dose COVID vaccine come to India? What Govt said. 2021. https:// www.indiatvnews.com/news/india/sputniklight- indialaunch-niti-aayog-russia-covid-vaccinecoronavirussecond-wave-latest-updates-703214

35. Kumar NR. Sputnik roll out begins, to cost ₹995 per dose. 2021. https://www.thehindu.com/news/ national/dr-reddy-administers-first-dose-of-sputnikvvaccine-in-india/article34555225.ece

36. Nkengasong JN, Ndembi N, Tshangela A, Raji T. COVID-19 vaccines: how to ensure Africa has access. 2020. doi: 10.1038/d41586-020-02774-8

37. Mehta T, Monnappa C, Jamkhandikar S, Abidi A. Overwhelmed India running short of COVID-19 vaccines. 2021. https://www.reuters.com/world/ india/indias-posts-record-daily-rise-covid-19cases-386452-2021-04-30/

38. TNN. Doctor among 4 held for selling vials illegally. 2021. https://timesofindia.indiatimes.com/city/ bengaluru/doctor-among-4-held-for-sellingvialsillegally/articleshow/82655043.cms

39. Dsouza DD, Quadros S, Hyderabadwala ZJ, Mamun MA. Aggregated COVID-19 suicide incidences in India: Fear of COVID-19 infection is the prominent causative factor. Psychiatry Res. 2020;290:113145. doi: 10.1016/j.psychres.2020.113145

40. Roy D, Tripathy S, Kar SK, Sharma N, Verma SK, Kaushal V. Study of knowledge, attitude, anxiety \& perceived mental healthcare need in Indian population during COVID-19 pandemic. Asian J Psychiatry. 2020;51:102083. doi: 10.1016/j.ajp.2020.102083

41. Joshi A, Bhaskar P, Gupta PK. Indian Economy Amid 
COVID-19 Lockdown: A Prespective. J Pure Appl Microbiol. 2020;14(Suppl 1):957-961. doi: 10.22207/ JPAM.14.SPL1.33

42. PTI. Tragic COVID-19 situation in India should raise alarm bells for all of us: UNICEF. 2021. https://health. economictimes.indiatimes.com/news/industry/tragiccovid-19-situation-in-india-should-raise-alarmbellsfor-all-of-us-unicef/82423819\#: : text=The $\% 20$ \%22tragic\%22\%20Covid\%2D19,UN\%20children's\%20 agency\%20has\%20said

43. Bassi LL. Allocating COVID-19 Vaccines Globally: An Urgent Need. JAMA Health Forum. 2021;2(2):e210105. doi: 10.1001/jamahealthforum.2021.0105

44. Kanitkar T. COVID-19 vaccine data analysis: At current rate of $2.2 \mathrm{mn}$ doses per day, India can only cover $30 \%$ population by end-2021. 2021. https://www. firstpost. com/india/covid-19-vaccine-data-analysis-atcurrentrate-of-2-2mn-doses-per-day-india-can-onlycover-30-population-by-end-2021-9562811.html

45. Desk EW. India's COVID-19 vaccines: All your questions answered. 2021. https://indianexpress. com/article/india/indias-covid-19-vaccines-all-yourquestionsanswered-7304271/
46. Radhakrishnan V, Sen S. Data | COVID-19 vaccination rate falls sharply in mid-April in India. 2021. https:// www.thehindu.com/data/covid-19vaccination-ratefalls-sharply-in-mid-april-in-india/ article34401369.ece

47. Wouters OJ, Shadlen KC, Salcher-Konrad M, et al. Challenges in ensuring global access to COVID-19 vaccines: production, affordability, allocation, and deployment. The Lancet. 2021;397(10278):1023-1034. doi: 10.1016/S0140-6736(21)00306-8

48. Fontanet A, Cauchemez S. COVID-19 herd immunity: where are we?. Nat Rev Immunol. 2020;20(10):583584. doi: 10.1038/s41577-020-00451-5

49. Costa DG, Peixoto JPJ. COVID-19 pandemic: a review of smart cities initiatives to face new outbreaks. IET Smart Cities. 2020;2(2):64-73. doi: 10.1049/ietsmc. 2020.0044

50. Sidhartha. India Inc calls for tougher national curbs amid surge. 2021. https://timesofindia. indiatimes.com/ business/india-business/indiainc-calls-for-toughernational-curbs-amid-surge/ articleshow/82363672. $\mathrm{cms}$ 